\title{
Namul, the driving force behind health and high vegetable consumption in Korea
}

\author{
Soon-Hee Kim ${ }^{1 *}$, Dae Young Kwon ${ }^{1}$ and Donghwa Shin ${ }^{2}$
}

\begin{abstract}
Namul (greens) is the driving force behind the fact that Korea has the highest per capita vegetable consumption in the world and also the secret to the longevity of Koreans. The word "Namul" refers to foods made by seasoning and mixing edible plants or leaves. Compared to other foods, a single serving of namuls contains a high quantity of vegetables because they tend to shrink in volume during the cooking process. The origin of namul in Korea can be traced back to a time when the country faced food shortages and people would forage for wild plants in fields or mountainous areas. However, with the addition of seasoning, namul evolved into a tasty dish and became an essential part of traditional Korean meals and the Korean diet. From the perspective of dietary diversity, namuls are a fantastic food as they contain a well-rounded selection of vegetables. Namuls are also rich in fiber and many phytochemicals, offering a number of health benefits. In an era where the world is grappling with the problem of excessive caloric intake, namuls have even greater value since they are low in calories while also very filling.
\end{abstract}

Keywords: Namul, Yangnyom (seasoning), Fiber, Longevity, Phytochemicals, Vegetables, K-diet

\section{Introduction}

Namuls, the driving force behind high vegetable consumption in Korea

Korea ranked number one globally for vegetable consumption in OECD data released in 2015 and 2017 (Fig. 1) $[1,2]$. Table 1 contains a list of the most common Korean foods [3], and vegetables can be used in most of these dishes. However, it is namul in particular that facilitate the high consumption of vegetables in Korea, and namuls are the primary reason why Korea is number one in terms of per capita vegetable consumption. Vegetables are typically parboiled or stir-fried in namuls, which causes their volume to shrink substantially. Accordingly, even though one portion of namuls served in a small dish may appear to contain only a meager quantity, this in fact amounts to a large volume of vegetables, and enables the consumption of far more vegetables than would be possible if they were eaten raw or in a salad. For example, a single serving of seasoned spinach in a typical Korean meal setting is made with $75-100 \mathrm{~g}$ of spinach, while a spinach salad usually

\footnotetext{
* Correspondence: shkim@kfri.re.kr

${ }^{1}$ Division of Nutrition and Metabolism, Korea Food Research Institute,

Wanju-kun, Jeollabuk-do 55365, Republic of Korea

Full list of author information is available at the end of the article
}

only contains $40-50 \mathrm{~g}$. In this sense, namuls allow people to eat twice the quantity of vegetables.

\section{Definition and ingredients of namul}

Broadly speaking, the word namul has two dictionary definitions. The first is "a word that encompasses all grasses or leaves that people can eat," and the second is "a food made by adding seasoning to edible grasses or leaves that are raw, boiled, or stir-fried" [4]. Accordingly, the word namul refers to both the ingredients used in namul dishes and foods made with such ingredients. When used to refer to ingredients, the word namul is similar to the more commonly used "vegetables," but the two concepts are not identical. The USDA (2010) classifies vegetables into five categories: (1) dark green vegetables, (2) red and orange vegetables, (3) beans and peas (legumes), (4) starch vegetables, and (5) other vegetables [5]. Among these categories, 1,2 , and 5 are used in Korea to make namuls, while seaweed, roots such as balloon flowers, and sprouts such as bean sprouts fall into the fifth category. While most vegetables come from artificially grown crops, namuls include not only planted vegetables but also a variety of grasses and parts of trees that grow naturally in mountains or fields. Namuls also include a variety of different parts of plants. For example, the roots of balloon flowers are used 


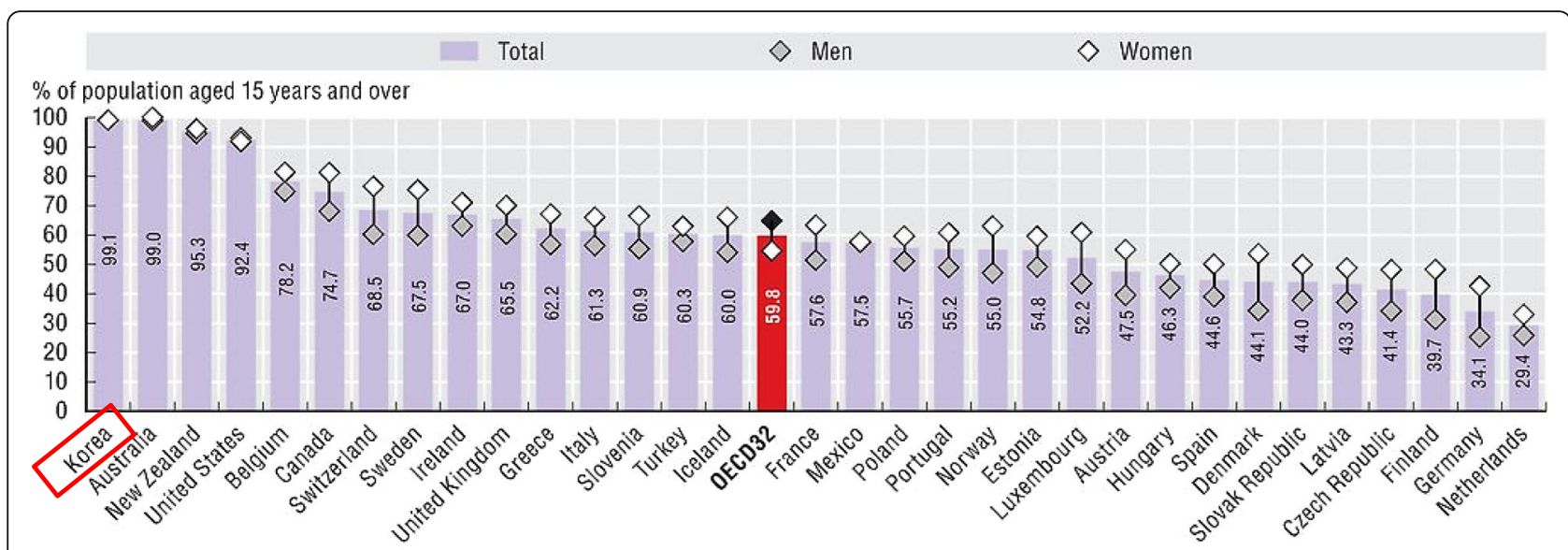

Fig. 1 Daily vegetable consumption among adults in OECD counties. Korea has been the global leader in per capita vegetable consumption for many years. Source: OECD Health Statistics 2017

Table 1 Categories of elements which are constructing in Korean diet (Korean bapsang) (Fig. 2), and representative Korean foods (K-food)

\begin{tabular}{|c|c|c|c|}
\hline Category & \multicolumn{2}{|c|}{ Sub-category } & Representative Korean foods (K-food) \\
\hline \multirow[t]{3}{*}{$\begin{array}{l}\text { Bap } \\
\text { (main dish) }\end{array}$} & \multicolumn{2}{|l|}{ Bap } & $\begin{array}{l}\text { Ssalbap (white rice, brown rice, black rice), boribap, kongbap, okokbap } \\
\text { (five-grain rice), nurungji }\end{array}$ \\
\hline & \multicolumn{2}{|l|}{ Juk } & Juk(rice juk), pumpkin juk, abalone juk, mungbean juk, red-bean juk \\
\hline & \multicolumn{2}{|c|}{ One-bowl foods } & $\begin{array}{l}\text { Bibimbap, theokmandutkuk (theok-kuk, mandutkuk), kuk-bap, kuksu (naengmyeon, } \\
\text { kalkuksu, kongkuksu, kuksujangkuk) }\end{array}$ \\
\hline \multirow[t]{2}{*}{ Kuk/Tang } & \multicolumn{2}{|l|}{ Kuk/tang } & $\begin{array}{l}\text { Doenjang-kuk, bukeokuk, kongnamulkuk, miyok-kuk, beaf/radish-kuk, torankuk, sundaekuk, } \\
\text { fish/maeuntang, Komtang (seollungtang, kalbitang), haemul-tang, samkye-tang, yukgaejang, } \\
\text { choowotang, dakdori (chicken-dori)-tang }\end{array}$ \\
\hline & \multicolumn{2}{|c|}{ Chigae/Chonkol } & Kimchi-chigae, doenjangchigae, cheongkukjangchigae, sundubuchigae, oigamjeong \\
\hline \multirow[t]{11}{*}{ Banchan } & \multicolumn{2}{|l|}{ Kimchi } & $\begin{array}{l}\text { Baechukimchi (bossamkimchi), kkakdugi, oisobagi, chonggakkimchi, mulkimchi } \\
\text { (dongchimi, nabakkimchi), yeolmukimchi, gatkimchi }\end{array}$ \\
\hline & \multirow[t]{2}{*}{ Namul } & Saengchae & Saengchae (radish, cucumber), juksunkyeojachae, buchumuchim, dalraemuchim, miyokmuchim, paraemuchim \\
\hline & & Sukchae & $\begin{array}{l}\text { Kong (soybean)-namul, sikeumchinamul, dorajinamul, kosarinamul, beoseotnamul, aehobaknamul, gajinamul, } \\
\text { chwinamul, naenginamul, gondrenamul, meowideulkkaejeuptang, japchae, tangpyeongchae (mukmuchim), } \\
\text { gujeolpan }\end{array}$ \\
\hline & \multirow[t]{8}{*}{ Banchan } & Chim & Kalbichim, suyuk, saengseonchim, sundae, kaetnipchim \\
\hline & & Gui & Kimgui, saengseongui, kalbi, bulgoki, samkyopsal, teok-kalbi, bukeogui, deodeokgui, borigulbi \\
\hline & & Jorim & Saengseonjorim, soegokijangjorim, kongjaban, yeongeunjorim, dubujorim \\
\hline & & Jeolim & Jangat-ji \\
\hline & & Bokeum & Myeolchibokeum, ojingobokeum, jeyukbokeum, theokboki, oibokeum (oibaetduri) \\
\hline & & Jeon & $\begin{array}{l}\text { Saengseonjeon, chaesonjeon (squash, eggplant, burdock, shiitake), hwayangjeok (pasanjeok), pajeon, } \\
\text { haemulpajeon, nokdubindaeteok, buchujeon, dubumuchim, yukjeon }\end{array}$ \\
\hline & & Hoe & Saengseonhoe, hongeohoe, kanghoe (green onions, water parsley), dureupsukhoe \\
\hline & & $\begin{array}{l}\text { Dried } \\
\text { Banchan }\end{array}$ & Bukak, ssam (loose leaf lettuce, perilla leaf, crown daisy) \\
\hline \multirow{3}{*}{$\begin{array}{l}\text { Jang/ } \\
\text { Yangnyom }\end{array}$} & \multicolumn{2}{|l|}{ Jang } & Jang (Doenjang, cheongkukjang, Kochujang, Kanjang) \\
\hline & \multicolumn{2}{|c|}{ Yangnyom } & Yangnyom (green onion, onion, chili, ginger), oil (sesame oil, perilla oil) \\
\hline & \multicolumn{2}{|l|}{ Jeotgal } & Jeotgal (shrimp, oyster, pollack roe), Kajamisikhae \\
\hline \multirow[t]{2}{*}{ Desserts } & \multicolumn{2}{|c|}{ Theok, hankwa } & $\begin{array}{l}\text { Shaped theok (songpyeon), pounded theok (injeolmi), steamed theok (baekseolki, ssukseolki, sirutheok, } \\
\text { jeungpyeon, yaksik), karae theok, pan-fried theok (hwajeon), boiled theok (gyeongdan), yakkwa }\end{array}$ \\
\hline & \multicolumn{2}{|c|}{ Drinks/beverages } & Sikhye, sujeongkwa, omija-cha, hwachae, sungnyung \\
\hline
\end{tabular}


in namuls, while for bracken and sweet potato it is the stalks, and young radish is used whole. For bean sprouts and mung bean sprouts, the sprouts of the plant are used, while young shoots are taken from bamboo and fatsia for use in namuls. In some dishes such as seasoned pepper leaves, only the leaves of the plant are eaten, while others such as seasoned pumpkin or eggplant use only the fruit of the plant. Compared to vegetables grown as crops, namuls encompass a greater variety of plant types and also allow people to consume different parts of plants.

\section{Historical background to the consumption of namuls and the secret that transformed namuls into a tasty dish}

Because crops could not be grown in the cold Korean winter, people would often run out of the food supplies they had stored by the end of the long winter. Newly planted crops could only be harvested in summer, or late spring at the earliest, which meant that spring was the season most prone to food shortages. The word chungunggi (season of spring poverty) was even coined to refer to this period of hunger. Accordingly, grasses growing on its own in the wild in spring were suitable for relieving hunger. Imwongyeongjeji, an ancient encyclopedia from the Chosun Dynasty, describes 260 types of famine relief plant resources that Koreans can eat, of which 187 appear to be types of namuls since they consist of leaves and stalks [6]. In a 1983 survey on "famine relief plants in Gangwon Province," 332 of 415 edible plants in Gangwon Province were young leaves or stalks that appeared in spring [7]. In this way, namuls made up the bulk of famine relief plants during the season of spring poverty and were a symbol of poverty and hunger.

However, as time went by, namuls developed from plants that simply staved off hunger into popular dishes that had their own unique flavors and aromas. After a long winter of eating nothing but kimchi and dried vegetables (mugeun-namul), fresh and aromatic spring namuls stimulated the taste buds and offered a refreshing change that only namuls could provide. As the weather started to warm up, it brought with it the season of spring fever which made people sluggish and listless, but eating spring namul was said to alleviate this condition. This is because namuls are rich in vitamins $B_{1}, B_{2}$, and $\mathrm{C}$, which boost energy metabolism and invigorate the body [8]. It is also true that compared to most vegetables chosen by humans for artificial cultivation, namuls are less pleasant to eat since many of the wild grasses or parts of trees used in namuls have a strong aroma or a bitter taste, and can be chewy and difficult to eat. Nevertheless, the secret that enabled namuls to develop into a "tasty" dish in Korea was the addition of seasoning. In Mokminsimseo, Jeong Yakyong gave the following advice. "In years with poor crops, the people replace food with namuls, but they are difficult to swallow without adding salt, and salt is expensive, so it is best to soak them in jang" [9]. In this context, jang refers to Doenjang, Kochujang, and Kanjang (soybean paste, red pepper paste, and soy sauce, respectively) as essential seasonings for namuls and demonstrates the important role that seasoning played in making namuls more edible at a time when people had no choice but to eat them out of hunger. This is similar to the concept of improving the taste of a salad by adding dressing. In addition to Doenjang, Kochujang, and Kanjang, other seasonings for namuls include red pepper powder, sesame, sugar, green onions, garlic, perilla oil, and sesame oil. Seasonings are selected and blended based on personal preference or the nature of the namuls being cooked, and bring out the flavor of namuls by blending with the original taste and aroma of the vegetables.

\section{The nutritional, health, and cultural significance of namuls to Koreans}

While wild grasses and the soft parts of trees could be picked to eat during times of famine, it was the wisdom of the ancient Korean people that enabled namuls to be turned into edible foods, and even delicious dishes, through the development of cooking methods. Although namuls were eaten during the spring famine, people also learned to dry and store namuls picked during summer and autumn in preparation for the long winter, when food supplies would run low. Bean sprouts are another product borne out of the ingenuity of the ancient Korean people. Although there were no vegetables in the fields in winter, bean sprouts could be cultivated simply by adding water to soybeans, which meant that they could be grown indoors. Cultivating bean sprouts was a wise decision, because they are rich in vitamin $C$, which soybeans do not contain, and provided a great source of vitamins in winter while also allowing people to eat fresh vegetables during a season in which they did not naturally grow.

Namuls were also used in special table settings prepared for celebrations of major holidays or each of the 24 divisions of the solar calendar, as well as ancestral rites ceremonies, which were considered very important in Confucianism and Buddhism. On January 15th in the lunar calendar, it is traditional to eat five-grain rice and dried vegetables, which are prepared by taking namuls dried the year before and soaking them in water before boiling them. Up to nine types of namuls are commonly used in these dishes, including dried slices of young pumpkin, eggplant, mushrooms, bracken, balloon flowers, dried radish, seasoned aster, and taro stems. Eating dried vegetables on this day was said to help ward off the heat during the upcoming summer, and modern science has confirmed that these dishes helped to 
provide extra fiber, minerals, and vitamin $\mathrm{D}$, which are nutrients that people often become deficient in during winter. The samsaek namuls prepared for major holidays or ancestral rites ceremonies consist of white, green, and brown namuls on a single plate, which is also esthetically pleasing. The white namuls include mung bean sprouts, seasoned balloon flowers, and seasoned radish, while the green ones consist of seasoned spinach and seasoned water parsley, and the brown ones are typically made with seasoned bracken or seasoned eggplant. Namuls were also offered for birthday celebrations, especially for young children, not cutting vegetables but maintained a long shape, because they wanted their children to live longer like long namuls [10].

Since namuls were borne out of poverty, they were also a symbol of honesty and represented selfsufficiency, being satisfied with one's current situation, and refraining from avarice or bribery. This closely followed the principles of integrity and morality in Confucianism, which was the core belief system in East Asia and the ruling ideology of the Chosun Dynasty at the time. Accordingly, although namuls were a symbol of poverty, they also embodied the idea of not being ashamed of one's circumstances and gave people a sense of comfort and pride. Ordinary people even dedicated songs to namul, such as the namul-taryeong (a taryeong is a type of traditional ballad), the balloon flowers taryeong, the changbu-taryeong, the swaying branches taryeong, and the "digging for namul song," which became work songs that laborers would sing to help them endure backbreaking work and resolve to support their families. Digging for namuls is even embodied in modern Korean songs such as Arirang Shepherd Boy and My Brother Is A Busker, which demonstrates that namuls are not merely a food, but a cultural element that is deeply rooted in the psyche of the working class.

\section{The status and importance of namuls in Korean diet}

As shown in Fig. 2, Korean food traditionally consists of a table setting which includes Bap (rice), Kuk (stew), kimchi, namuls, and side dishes [11]. Bap is the staple food which is eaten with every meal, and Kuk, kimchi, and namuls are usually present as well, while the side dishes are an accompaniment that differs in type and number for every meal. Since namuls are one of the core elements of Korean diet and are served at almost every meal year-round, they are a major contributing factor to Korea's high vegetable consumption. This is due to both the quantity consumed in a single serving and the number of servings per day. In addition to being a regular part of most meals, namuls are also an essential inclusion in food served on major holidays or festive occasions.

The discussion above describes how namuls are a product of Korean history and have continued to develop throughout Korean history. In addition to this, namuls are closely intertwined with Buddhist culture and traditions. Namuls play a major role in providing a

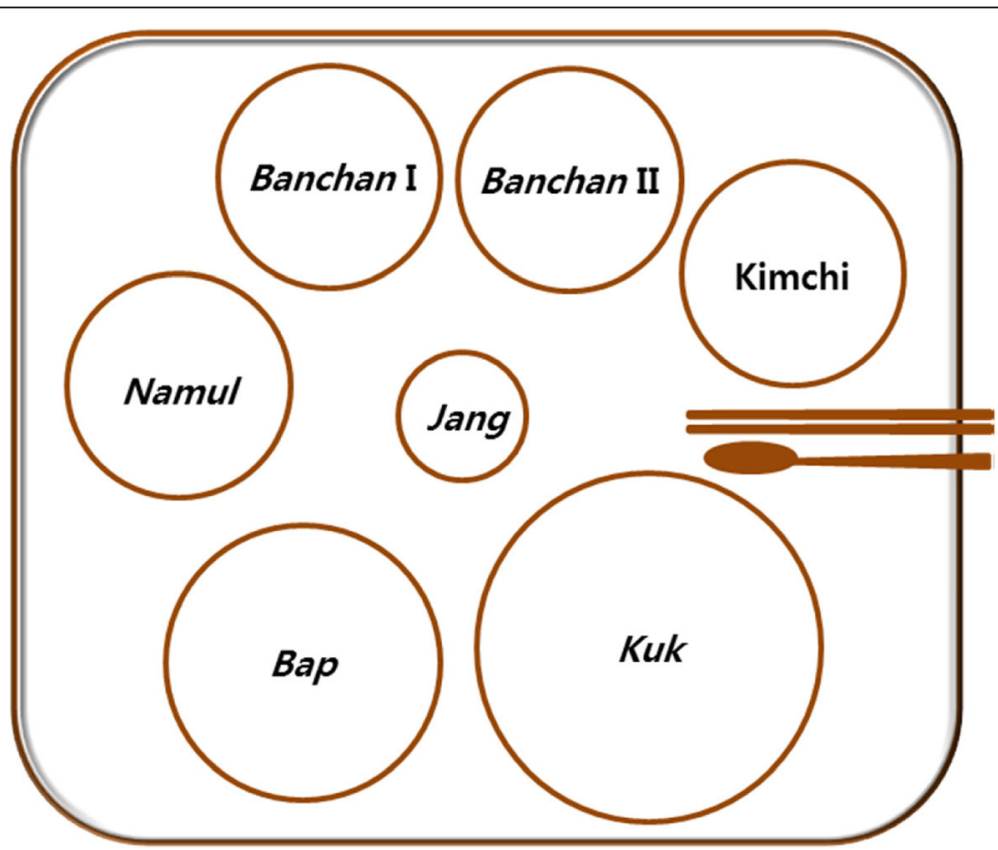

Fig. 2 Typical structure of a table setting in traditional Korean meals. Korean food consists of bap (rice), kuk (stew), and side dishes served simultaneously. Bap is always served, while kuk, kimchi, and namuls are almost always present, and side dishes consist of several steamed dishes, roast dishes, dishes boiled in soy sauce, or stir-fried dishes, which vary in type and quantity. Source: Kim et al. [11] 
source of food and promoting nutrition and health in Korea, and they are an integral part of the Korean diet. This paper aims to provide a comprehensive examination of the history and types of namuls, as well as methods for cooking namuls and their nutritional functions.

\section{Main text}

\section{History and terminology of namuls}

Although it is not possible to determine the exact point at which namuls were first consumed in Korea, The Heritage of the Three States, written by Il-yeon, contains a description of the birth myth of Gochosun that features a scene where the characters eat mugwort and garlic. This suggests that Koreans were eating mugwort and garlic as early as 5000 years ago [12]. Lee Gyu-bo's Donggukisanggukjip, written in the middle part of the Goryeo kingdom, contains a poem titled Gapoyukyeong, which is about six types of vegetables grown in a vegetable patch (cucumber, eggplant, radish, green onion, curled mallow, and pumpkin). The poem praises the beautiful exterior and fantastic taste of these vegetables, which are still enjoyed by Koreans today and mainly grown in vegetable patches. This poem suggests that vegetables were grown in a similar fashion back then. In particular, the poem mentions that radish can be eaten throughout the winter if pickled with salt. This demonstrates that Koreans had already developed techniques which allowed radish to be stored in winter, providing a fresh and crunchy treat at a time when the only other vegetables available to be eaten were kimchi and dried vegetables. Nongga-wollyeongga, a book from the Chosun Dynasty which contains records of the farm work to be performed each month and customs from that era, states in January unit "If you garnish radish with green onion and water parsley, it looks fresh and would not even compare with the five pungent herbs. Boiling dried wild vegetables transforms them into a meat dish," which claims that the taste of dried vegetables stored during winter better than meat [13]. February unit also says "The greens in the mountains are still too early to eat, so dig up vegetables in fields and eat them. Korean lettuce, lettuce, curly dock and wormwood. Stew made with wild chives kimchi and shepherd's purse is good for the stomach." This shows that people were aware of the season in which edible namuls grew in mountains and fields, picked such namuls at the appropriate time, and ate a variety of namul. These records also contain advice on the best time to plant vegetables, optimal cultivation methods, and the time at which certain harvested vegetables should be dried and stored, and the types of namuls and methods described are similar to those have been passed down to modern times. Detailed records of cooking methods for namuls are contained in Jeungbo- sallimgyeongje, an ancient book on agriculture, and Eumsik-dimibang, an old cookbook, and these recipes are largely similar to the ones used today.

The words or old terms used to describe namuls and vegetables include "namsae," which meant vegetables cultivated for human consumption, and "puseonggwi," a term that referred to all vegetables that were cultivated by humans or grew naturally in mountains or fields. This means that puseonggwi was a concept that included namsae. In North Korea, "namuls" refers to "seasoned dishes made by seasoning namsae or edible wild namuls (greens)," and namul can be broadly categorized into "cultivated namsae, edible wild namuls from the mountains, and edible wild namuls from fields," which demonstrates that namsae is used as an encompassing term for cultivated crops and is different from the concept of wild edible namuls [14]. Namsae was also called a chaema (菜麻), and the term "chaema-bat," a field for growing chaema, often appears in ancient documents from the Chosun Dynasty. In some documents written in Chinese script, the characters 羅物 (namul) were used for namul. Accordingly, some have suggested that the term namul is derived from the phrase "sillaui-mulgeon" (goods of Silla). However, this view is not supported by evidence [15]. Prior to the invention of the Korean script, Chinese characters were the only tool for writing in Korea, and it was common to choose homonyms from among Chinese characters for written documents. It appears that this has occurred in this case as well.

There are also several words that refer to the act of picking namuls. While there is only a single verb, "chaechuihada," that uses Chinese characters, there are many more words for picking in pure Korean, including "kaenda (캔다)" for picking shepherd's purse and deodeok roots, "ddeudneunda (뜯는다)" for picking mugwort by hand, and "ggeokneunda (꺾는다)" for picking bracken and "bbobneunda (뽑는다)" for picking garlic stems. The fact that different verbs were used for picking different types of namuls or different parts of the plant indicates the significance of namuls to Koreans and is evidence of the country's long history of consuming a variety of namuls.

\section{Types of namuls and cooking methods}

Namuls can be broadly divided into saengchae (raw vegetables) and sukchae (cooked vegetables) (Fig. 3). Saengchae is a dish made by mixing raw vegetables with seasonings, similar to a salad (while a salad is an independent entire dish in itself, saengchaes are a side dish eaten alongside a staple food such as rice), and sukchaes are a seasoned food produced by adding heat through methods such as parboiling or stirfrying. Sukchaes can be further divided into those where raw vegetables are immediately cooked and 


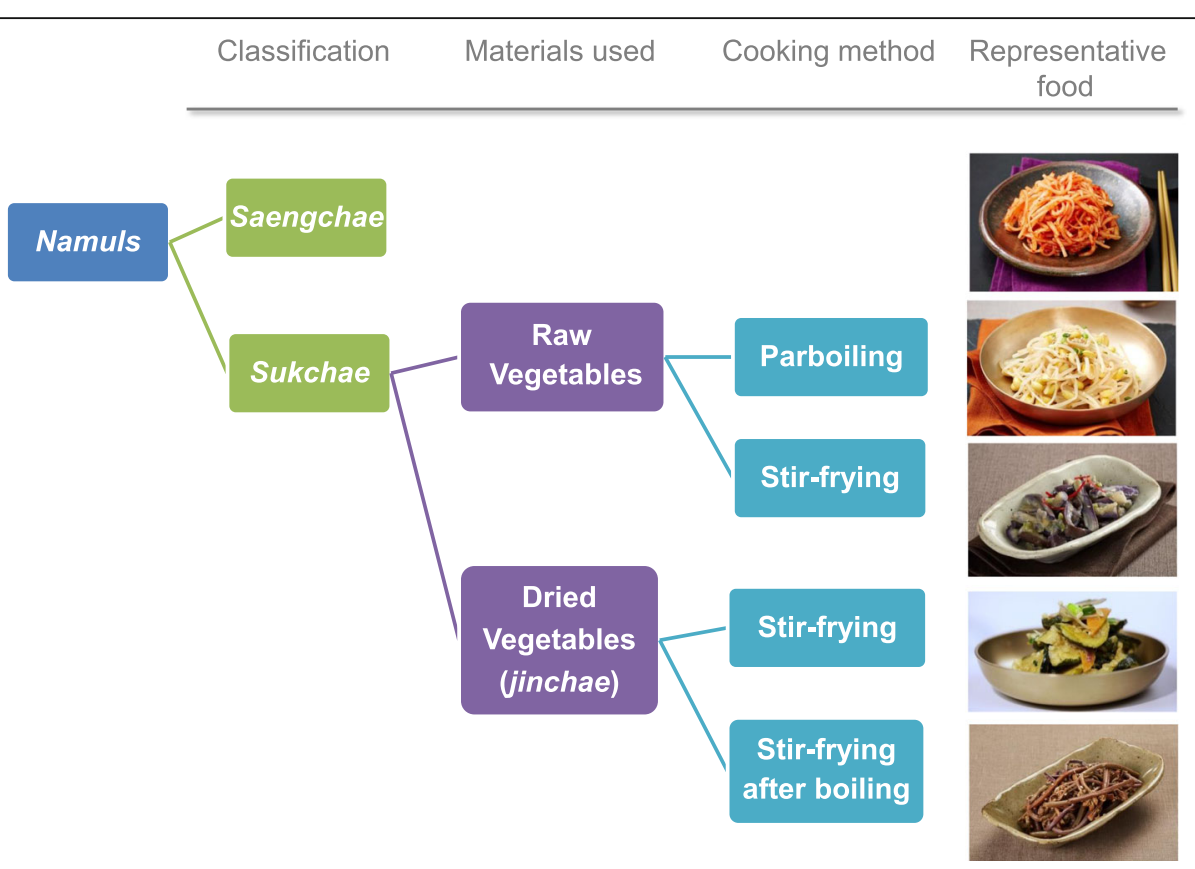

Fig. 3 Types of namuls and common foods of each type. Namuls can be classified into sukchae or saengchae depending on whether the ingredients are cooked or not prior to being served. Sukchae can be further divided based on whether they use fresh raw vegetables or namuls that have been dried and stored, and recipes can vary based on personal preference and the nature of the ingredients. Individual recipes do not have separate names and are all encompassed by the general term "sukchae." The picture on the right shows the most common dishes for each type of namuls. From top to bottom, the names of the foods are shredded white radish, seasoned bean sprouts, seasoned eggplant, seasoned young pumpkin, and seasoned bracken

seasoned, such as bean sprouts, and those that are dried and stored before being soaked in water and seasoned, such as seasoned bracken. Because it was difficult to obtain vegetables during the long Korean winter, vegetables picked in summer or autumn were dried and stored for use as a supply of vegetables during winter. Namuls made with dried and stored vegetables are called jinchae, which means dried vegetables.

The cooking methods for saengchaes and sukchaes are self-explanatory, but what they have in common is the addition of seasoning (Fig. 4). Saengchaes are seasoned

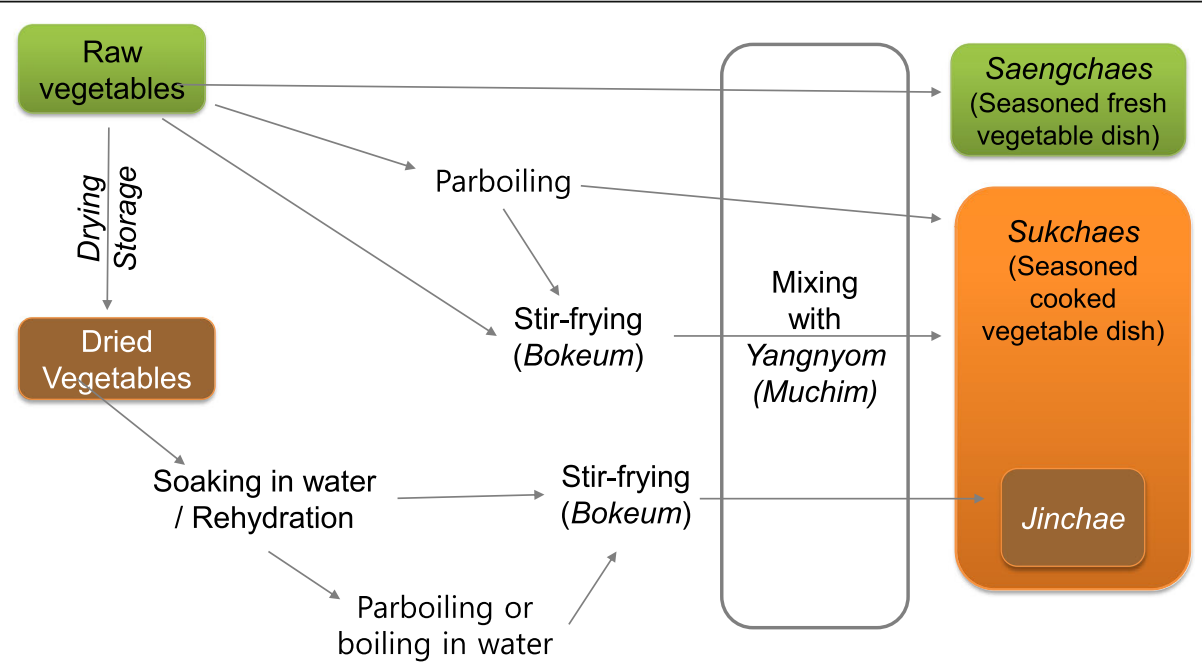

Fig. 4 Cooking methods for namuls. The type of namuls is determined by the type of ingredients and the cooking method employed. Saengchaes are prepared by adding seasoning to fresh vegetables, while sukchaes are made by adding seasoning after parboiling or stir-frying. Sukchaes can be made with fresh vegetables or those that have been stored and dried. When dried vegetables are prepared, they are first soaked in water, then parboiled or stir-fried, and seasoned. Because these dishes involve a cooking process, they all fall into the category of sukchaes and are also known as jinchae 
after the raw ingredients are cleaned, while sukchaes go through a cooking process such as parboiling or stirfrying with oil before the seasoning is added. Parboiling is mainly used for namuls that consist of leaves, vegetables with a strong aroma, or vegetables with a weak structure. When stir-frying, the seasoning is added while cooking, so that it naturally seeps into the vegetables as they cook and blends with their flavor. Seasonings that lose their smell when heated, such as sesame oil, perilla oil, and sesame, are added once the food has already been heated so that the aroma is preserved to the fullest extent. Jinchae can also be divided into dishes where dried vegetables are stir-fried after being soaked and dishes where the vegetables are first soaked, then parboiled or boiled once again, and finally stir-fried. Boiling is used in the latter case to soften namuls that are rough or chewy (Fig. 4).

Seasonings for namuls include jang such as Doenjang, Kochujang, and Kanjang, as well as red pepper powder, sesame, sugar, green onions, garlic, perilla oil, and sesame oil, and are selected and blended based on personal preference or the nature of the namuls being cooked. As one likes, namuls that utilize bean sprouts can be cooked white without adding red pepper powder, or red and spicy with chili powder. Seasoned shepherd's purse can also be prepared with red chili-pepper paste and vinegar or soybean paste depending on personal preference. Even with the same raw ingredients, adding different types of seasoning to the vegetables can produce different tastes and unique dishes, and the same vegetables can be eaten either raw or cooked. For example, pimpinella can be eaten either raw or in a cooked dish, and the two dishes have completely different tastes and textures. Accordingly, namuls can be enjoyed in as many different ways as there are vegetables multiplied by the number of seasonings, which adds greater diversity to Korean food and allows people to eat namuls as part of nearly every meal without tiring of the taste (Fig. 5).

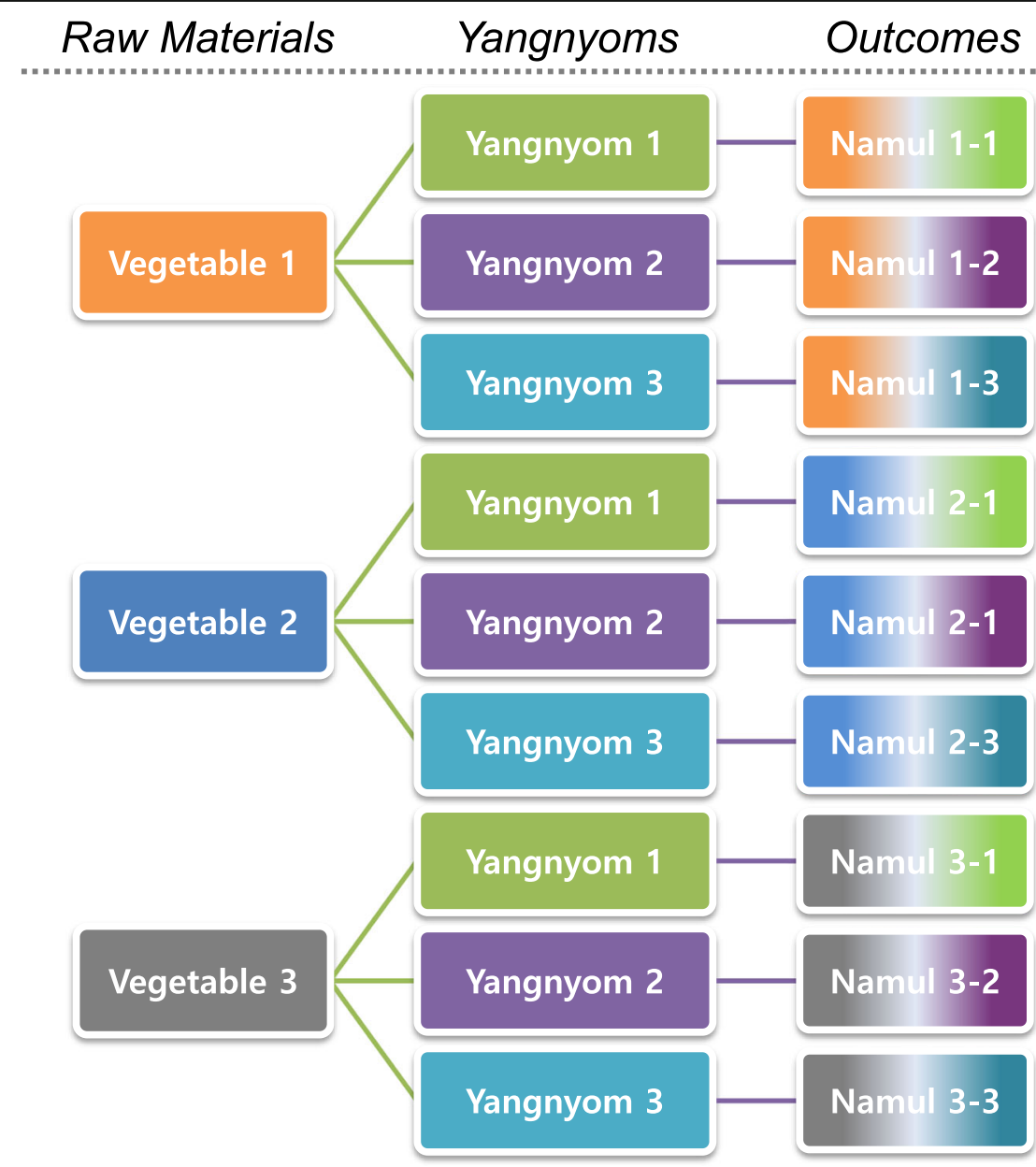

Fig. 5 The diversity of namuls. Seasoning is created by selecting and blending a mix of condiments based on personal preference and the nature of the vegetables used. Different flavors and types of namuls can be produced with different seasonings, even if the same vegetables are used. Accordingly, namuls can be prepared in as many different ways as there are vegetables multiplied by the number of seasonings, which allows people to eat namuls as part of nearly every meal without tiring of the taste 


\section{Health benefits of namuls}

Most of the ingredients used in namuls are plants that contain functional components, which makes them healthy ingredients. However, it is not just namuls themselves that are healthy, but also the seasoning that is added. As depicted in Fig. 4, all varieties of namuls contain seasoning, which means that the seasoning is infused into the namuls. The seasonings used in namuls include fermented jangs such as doenjang, kanjang, and kochujang; medicinal plants such as red pepper powder, green onions, garlic, and ginger; and vegetable oils such as perilla oil and sesame oil. Several of these seasonings are selected and blended, taking into account personal preference and the flavors that best match with the original taste and aroma of the vegetables used. These seasonings not only enhance the flavor of the namuls, but red pepper powder, red pepper paste, and soy sauce add color to dishes, and sesame seeds add a savory taste in addition to an esthetic element. Sesame oil and perilla oil add a savory aroma to namuls. In this sense, seasoning adds to the taste, look, and aroma of namuls, but more importantly, almost all of the ingredients used in seasonings are known to have functional components. The green onions, garlic, ginger, and red peppers that make up the bulk of ingredients used in seasonings are rich in sulfides, thiols, diallyl sulfide, allicin, capsaicin, and gingerol, which are known to have an antiinflammatory and anti-cancer effect and also lower blood cholesterol levels $[8,16]$. Other fermented ingredients, such as doenjang, kanjang, and kochujang, also provide the unique health benefits offered by fermented foods [8]. Perilla oil contains so much $\alpha$-linolenic acid, a type of polyunsaturated fatty acid (PUFA), that this compound accounts for $40-64 \%$ of all the fatty acid contained within. This acid is known to promote cardiovascular health and have a positive impact on arteriosclerosis, fatty liver, and hyperglycemia [17, 18]. Sesame oil is infused with the functional compounds sesamin and sesamol, which are known antioxidants, and other research has found that it lowers lipid concentrations in the blood and liver [19].

In this sense, namuls are naturally healthy due to the fact that they are comprised of ingredients and seasonings that offer a range of health benefits. However, there are three main reasons why namuls are good for human health. Namuls are rich in fiber, rich in phytochemicals, and very filling while having a low caloric content.

\section{Fiber}

The healthy diet guidelines published by Harvard Medical School contain seven items in total, two of which are related to vegetables and fiber [20]. The guidelines recommend consuming five or more servings of fruit and vegetables per day and choosing fruit and vegetables of different types and colors. The guidelines also advise against eating refined carbohydrates, and instead eating whole grains, whole vegetables, fruits, beans, and nuts. This advice was given with the fiber contained in nonprocessed vegetable-based ingredients in mind. One of the main features of the Mediterranean diet, which is known around the world as a healthy diet, is that it is low in saturated fat and high in fiber. The DASH diet also includes at least four to five servings of vegetables and seven to eight servings of grains, at least half of which should be whole grains, and encourages people to consume a minimum of $30 \mathrm{~g}$ of fiber per day [21].

A national health survey carried out in Korea in 2014 found that the average daily intake of dietary fiber by Koreans was $23.2 \mathrm{~g}$ per $2000 \mathrm{kcal}$, and the main contributor to daily fiber consumption was vegetables, with fiber obtained from vegetables and grains accounting for more than half of the total fiber consumption [22]. This figure is higher than the national averages of the USA (17-18 g) and Japan (15-18 g) [23].

Although some namuls are made with the fruit or roots of plants, many dishes use the stalks or leaves, which generally have a much higher fiber content than the fruit. In particular, many dried vegetables are cooked after being soaked in water for a long time and boiled. This process helps to soften their chewy texture, a feature which is present due to their rough exterior and high fiber content. Table 2 is an extract taken from a study that analyzed 150 commonly eaten foods in Korea, and outlines the fiber content of ingredients used in namuls [22]. The foods in the shaded areas are used in jinchae and contain $5.01 \mathrm{~g}$ of fiber per $100 \mathrm{~g}$ of fresh edible parts, which is far higher than the $3.45 \mathrm{~g}$ average across all vegetables listed. Considering the frequency with which namuls are consumed, the quantity of vegetables contained in each serving, and the diverse range of ingredients used, namuls clearly comply with the global healthy diet guidelines listed above and play a significant role in contributing to fiber consumption in Korea.

Fiber promotes intestinal health while also improving blood sugar and lipid levels, but a meta-analysis of 22 cohort studies on chronic diseases that are plaguing the world also found that a 7-g increase in daily fiber consumption reduced the risk ratio for CVD and CHD to 0.91 (confidence intervals of 0.88 to 0.94 for CVD and 0.87 to 0.94 for CHD) [24]. In support of this, a survey conducted in 2015 found that the CVD mortality rate in Korea was less than 220 per 100,000 people, one of the lowest figures in the world [25].

\section{Phytochemicals and a diverse range of nutrients}

All plants produce secondary metabolites to protect themselves against damage from microorganisms and insects, and these compounds, known as "phytochemicals," 
Table 2 Fiber content of the main ingredients used in namuls (from among commercial foods in Korea)

\begin{tabular}{|c|c|}
\hline Food & $\begin{array}{c}\text { Total fiber per } 100 \mathrm{~g} \text { in edible } \\
\text { parts (g) }\end{array}$ \\
\hline Perilla leaves & 7.9 \\
\hline Seasoned aster & 5.8 \\
\hline Shepherd's purse & 5.68 \\
\hline Garlic stems & 5.35 \\
\hline Bracken (cooked) & 5.14 \\
\hline Deodeok & 5.1 \\
\hline Green laver & 4.6 \\
\hline Red pepper leaves & 4.56 \\
\hline Taro stems (cooked) & 4.41 \\
\hline Balloon flowers & 3.99 \\
\hline $\begin{array}{c}\text { Sweet potato stems } \\
\text { (cooked) }\end{array}$ & 3.9 \\
\hline Spinach & 3.24 \\
\hline Chard & 2.95 \\
\hline Enoki mushrooms & 2.94 \\
\hline Bean sprouts & 2.55 \\
\hline Parsley & 2.46 \\
\hline $\begin{array}{c}\text { Shiitake mushrooms } \\
\text { (raw) }\end{array}$ & 2.44 \\
\hline Crown daisies & 2.27 \\
\hline Radish tops & 2.26 \\
\hline Chives & 2.11 \\
\hline Eggplant & 1.85 \\
\hline Lettuce & 1.83 \\
\hline Mung bean sprouts & 1.81 \\
\hline Oyster mushrooms & 1.7 \\
\hline Radish & 1.49 \\
\hline Cucumbers & 1.46 \\
\hline Average & 3.45 \\
\hline
\end{tabular}

The shaded areas represent ingredients used in dried vegetables (jinchae) have also received attention for their beneficial role in protecting humans from disease. Although all plants have phytochemicals, plants that grow in the wild in difficult conditions (and thus face a greater number of stressors) produce more phytochemicals than those grown by humans in artificial environments. As described above, the scope of namuls is not limited to cultivated vegetables. Certain wild grasses and parts of trees are also used in namuls, and a variety of plants growing in mountains and fields are especially popular in spring. In addition to land-based plants, sea-based plants including laver, seaweed, green laver, and hijiki are also used as ingredients in namuls. In particular, many wild edible namuls have a unique scent, and the most common compounds found in aromatic volatile compounds in namuls are sesquiterpenes, monoterpenes, aldehydes, alkanols, and alkanes [26-28]. It has recently been discovered that these compounds have an antioxidant, antibiotic, and anti-inflammatory effect [29, 30]. The fact that many wild plants are used in namuls, and many of those plants have a unique scent, suggests that namuls contain a greater quantity and more diverse range of phytochemicals than artificially cultivated vegetables.

It has also been demonstrated that the natural colors found in vegetables are another kind of phytochemicals, and these natural color compounds have a number of beneficial functions. This is why nutritionists recommend eating foods of five different colors every day [20] and promote healthy eating through slogans such as "eating rainbow food." For example, black soybeans are better for your health than yellow soybeans, at least in terms of phytochemicals. Black soybeans are richer in total phenolic contents, total flavonoid contents, and monomeric anthocyanin than yellow soybeans, and higher levels of ferric reducing antioxidant power, ABTS radical scavenging activity, and DPPH free radical scavenging capacity have also been found in black rather than yellow soybeans [31]. The reason why berries such as blueberries are popular as healthy foods is the anthocyanin phytochemicals found in their dark color. Namuls are equipped with conditions that contain high phytochemicals due to their deep-green color, wildgrown plants, and high aromatic compounds. Namul dishes also contain a high volume of vegetables in absolute terms, which is why it can be surmised that they are infused with more phytochemicals than ordinary vegetable dishes.

The basic principle of healthy diets recommended by nutritionists is eating a variety of foods. Since there is no magic food that contains all essential nutrients, eating a variety of foods allows different foods to complement each other. For example, one could make up for a lack of a certain nutrient in food A by eating food B which is rich in that nutrient. Eating a variety of foods allows 
people to consume a balanced range of different nutrients, and the same applies to phytochemicals. Different plants contain different types and quantities of phytochemicals, and each type of phytochemicals has a different effect. For example, seasoned spinach contains saponin and lutein, while seasoned balloon flowers contain platycodin and triterpenoidsaponins, seasoned bracken is rich in kaempferol 3-O-glucoside, mushrooms contain lentinan and erithadenine, seasoned pumpkin has $\beta$-carotene, seasoned eggplant contains anthocyanin, seasoned aster is rich in lutein and zeazanthin, seasoned shepherd's purse contains inositol and diosmin, and seasoned thistle contains silymarin and pectolinarin [10]. It has been proven that quercetin is highly effective at improving blood pressure and blood sugar levels, while also lowering plasma C-reactive protein concentration [3234], and saponin has an anti-cancer effect by stimulating apoptosis and suppressing metastasis [35]. Therefore, a balanced diet consisting of all of these compounds can lead to improvement in a variety of biological functions through phytochemicals, including boosted immunity, greater insulin sensitivity, and antioxidant, anti-aging, and anti-cancer effects. Since further research may shed more light on the healthy functions of phytochemicals in the future, it is possible that eating a variety of namuls could lead to additional functional benefits outside of those described.

\section{Low calories vs high satiety}

Another one of the health benefits of namuls is their low caloric content. A single serving of namuls contains far fewer calories than most other foods. Most of the calories in namuls come from oil, and namuls are typically cooked with sesame oil or perilla oil in Korea. These oils are known for their antioxidant effect and positive impact on cardiovascular disease due to the fact that they contain functional compounds and are rich in PUFA. This means that namuls are not only low in calories, but the calories they do contain come from substances that benefit the body. Namuls are highly effective for weight loss, as they are low in calories while also very filling. While reducing caloric intake is an important part of weight loss, being able to satiate oneself is also important for maintaining a diet long-term. The reason why namuls are filling despite their low caloric content is the high amount of fiber found in vegetables, which are namuls main ingredient. Holt et al. measured the compounds that influence satiety in 38 everyday foods and found that fiber was second only to water when it comes to the correlation with feeling full [36]. While Holt mainly focused on a western diet and looked at only a small number of foods, a similar study using his methodology on foods commonly consumed in Korea found that fruit and vegetables led to higher satiety than other foods [37].
Other research has also found that along with protein, fiber has the greatest impact on feeling full after eating. Fiber adds volume to foods and slows down gastric emptying, which causes people to feel less hungry. In addition to this, fiber slows down digestion, causing blood sugar to remain at a constant level instead of suddenly spiking, which also reduces feelings of hunger [38, 39]. When viewed as a whole, research findings on the relationship between fiber and hunger, satiety, and energy intake suggest that consuming $14 \mathrm{~g}$ more fiber per day leads to a reduction in energy intake of $10 \%$ and weight loss of $1.9 \mathrm{~kg}$ [40].

\section{Staple foods among Korean centenarians}

The above section examined the reasons why namuls are good for human health, and it turns out that namuls are indeed a popular food choice among people who have lived long, healthy lives. A survey conducted on 91 individuals aged over 90 in regions of Korea known for longevity, including Damyang, Gokseong, and Gurye, found that namuls were the second most popular food [41]. Considering the fact that rice topped the list, this shows that namuls were the favorite side dish among people of such an advanced age. Another study on 71 centenarians across ten other regions found that the most popular foods were namuls, rice, jeon (Korean pancakes), and jorim (dishes boiled in soy sauce), with 93.7\% of respondents stating that they liked namuls [42]. An examination of the main side dishes consumed by centenarians found that namuls were overwhelmingly preferred over other types (Fig. 6).

\section{Conclusion}

A study of 35 industrialized countries published in Lancet in 2017 predicted that Korea would become the global leader in longevity by 2030 [43]. At present, Korea is already within the global top ten in terms of lifespan, and the same holds true for health-adjusted life expectancy (HALE) [44]. Elderly Koreans and the scholars that research them believe that this is thanks to the consumption of a variety of vegetables, primarily namuls, and fermented foods such as jang and kimchi [45, 46]. Although the origin of namuls dates back to a time when Koreans used herb roots and tree bark to resolve their hunger in times of famine, the addition of seasoning to these dishes has caused namuls to develop into a popular and proud part of the Korean diet. Namuls help to promote dietary diversity by enabling the consumption of a balanced range of vegetables, and the fact that these vegetables become compressed during the cooking process is a major contributor to the high consumption of vegetables in Korea. Namuls are also rich in fiber and phytochemicals and are low in calories while providing a high level of satiety, making them useful for health 


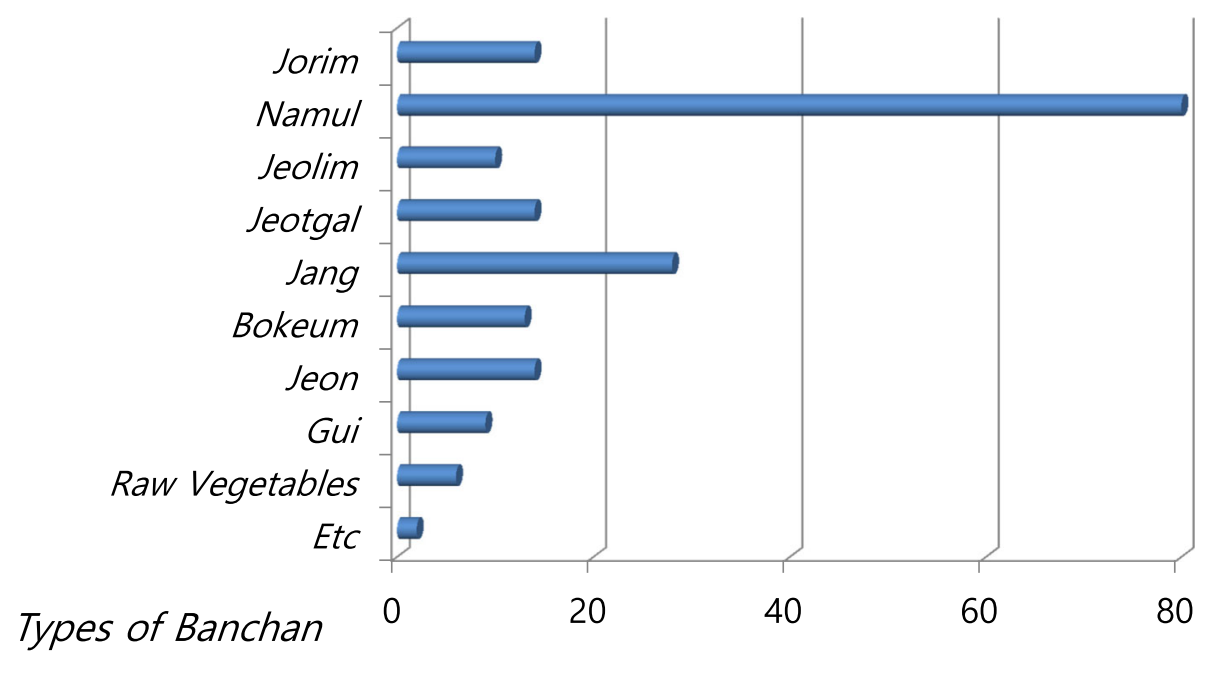

Frequency of ingestion

Fig. 6 Types of side dishes consumed by centenarians and frequency of consumption. Namuls are consumed at a far higher rate than other types of side dishes. Source: Lee [42]. Jorim: dishes boiled in kanjang (soy sauce). Ingredients such as meat, seafood, tofu, or vegetables are marinated, usually with kanjang, then cooked over a low flame. Jeolim: pickled dishes. Pickling was developed so that ingredients which could previously only be eaten in season could be stored and eaten year-round. This involves placing vegetables in salt, vinegar, or jang such as soy sauce, soybean paste, or red pepper paste so that the flavor seeps into the vegetables and they do not rot. The process of maturation adds a new flavor to the dishes [46]. Jeotgal: salted fermented seafood used to enhance its flavor and appetite rather than increase the nutritional value of the food. Jang: jang is a group of traditional Korean fermented foods made with soybeans and includes soybean paste, soy sauce, red pepper paste, and chongkukjang. While these foods are most often used to adjust or enhance the taste of side dishes and kuk, they can also be used as standalone dipping sauces for vegetables, raw fish, or meat. Bokeum: stir-fried dishes. Vegetables or meat are stir-fried in a hot pan with a pinch of oil. Fried dishes were traditionally rare in Korea due to the scarcity of oil, so stews or stir-fried dishes were cooked by adding only a small amount of oil to the pan. Jeon: Korean pancakes. Fish, vegetables, or meat are cut into thin pieces, salted, and then wrapped in a mixture of flour and egg, before being heated in a frying pan with oil into a flat shape. Gui: roast dishes. Ingredients are marinated and then roasted or served as cooked side dishes after adding salt and grease. Roast dishes can be salted or marinated with soy sauce or red pepper paste

maintenance and weight loss. Namuls are one of the most frequently consumed foods among those who remain in good health at an advanced age. In an era marked by excessive energy intake and the resulting problems of obesity and metabolic diseases, as well as greenhouse gas emissions caused by livestock rearing to fuel meat consumption, namuls have the potential to serve as an alternative solution.

\section{Authors' contributions}

SHK organized the content of this paper, searched for the material, reviewed the contents, and wrote the manuscript. DYK looked up and examined the contents of Korean ancient books about namuls. DHS organized the content and supervised this study. All authors read and approved the final manuscript.

\section{Funding}

This research was supported by the Main Research Program E0150302-05 of the Korea Research Food Institute (KFRI) funded by the Ministry of Science, ICT \& Future Planning.

\section{Availability of data and materials} Not applicable.

\section{Competing interests}

The authors declare that they have no competing interests.

\section{Author details}

${ }^{1}$ Division of Nutrition and Metabolism, Korea Food Research Institute, Wanju-kun, Jeollabuk-do 55365, Republic of Korea. ${ }^{2}$ Jeonbuk University, Jeonju, Jeollabuk-do, Republic of Korea.

Received: 12 October 2019 Accepted: 21 October 2019 Published online: 14 May 2020

References

1. Organisation européenne de coopération économique. Health at a glance 2017: OECD indicators. OECD. 2017.

2. Organisation européenne de coopération économique. Health at a glance 2015: OECD indicators. OECD. 2015

3. Kwon DY. Diet in Korea. Seoul. 2019 (In press)

4. Standard Korean Language Dictionary. National Institute of Korean Language. https://stdict.korean.go.kr/main/main.do. Accessed 22 Sept 2019.

5. Dietary Guidelines for Americans, 2010, 7th ed. U.S. Department of Agriculture and U.S. Department of Health and Human Services, Washington, DC. https://www.dietaryguidelines.gov. Accessed 22 Sept 2019.

6. Seo YG. Imwonkyungjeji. Korea (Choseon Dynasty); 1835.

7. Kim CR. Study on famine relief food-focused on Gangwon Province. J Kwandong Univ. 1983;11.

8. Pak KY, Kwon DY, Lee KW, Park S. Korean functional foods: composition, processing, and health benefits. Boca Raton: CRC Press, Taylor \& Francis Group; 2018.

9. Jeong YY. Mokminsimsuh. Korea (Choseon Dynasty); 1818.

10. Kwon DY, Lee YE, Kim MS, Kim SH. Speak of K-diet: history, culture, and health. Korea Food Research Institute; 2017.

11. Kim SH, Kim MS, Lee MS, Park YS, Lee HJ, Kang SA, et al. Korean diet: characteristics and historical background. J Ethn Foods. 2016;3:26-31.

12. II Y. Memorabilia of the three kingdoms. Korea (Koryo); 1281. 
13. Jeong HY. NongGa-Wolryungga. Korea (Choseon Dynasty); 1786-1855.

14. Chosunryori. Joseonryori-hyeophoi, Pyongyang. http://cooks.org.kp/index. php. Accessed 22 Sept 2019.

15. Park JB. A mouthful of Namul in a weary palate. Chosun Ilbo, Seoul; 2017.

16. Surh YJ. Cancer chemoprevention with dietary phytochemicals. Nat Rev Cancer. 2003:3(10):768-80.

17. Rao S, Abdel-Reheem M, Bhella R, McCracken C, Hildebrand D. Characteristics of high alpha-linolenic acid accumulation in seed oils. Lipids. 2008:43(8):749-55.

18. Bhathena SJ, Ali AA, Haudenschild C, Latham P, Ranich T, Mohamed Al, et al. Dietary flaxseed meal is more protective than soy protein concentrate against hypertriglyceridemia and steatosis of the liver in an animal model of obesity. J Am Coll Nutr. 2003;22(2):157-64.

19. Namiki M. Nutraceutical functions of sesame: a review. Crit Rev Food Sci Nutr. 2007:47(7):651-73.

20. Willett WC, Skerrett PJ, Giovannucci EL, Callahan M. Eat, drink, and be healthy: the Harvard Medical School guide to healthy eating. Free Press New York; 2005

21. Skerrett PJ, Willett WC. Essentials of healthy eating: a guide. J Midwifery Womens Health. 2010;55(6):492-501.

22. Yeon SY, Oh K, Kweon S, Hyun T. Development of a dietary fiber composition table and intakes of dietary fiber in Korea National Health and Nutrition Examination Survey (KNHANES). Korean J Community Nutr. 2016; 21(3):293-300

23. Stephen AM, Champ MM, Cloran SJ, Fleith M, van Lieshout L, Mejborn $H_{\text {, }}$ et al. Dietary fibre in Europe: current state of knowledge on definitions, sources, recommendations, intakes and relationships to health. Nutr Res Rev. 2017;30(2):149-90.

24. Threapleton DE, Greenwood DC, Evans CE, Cleghorn CL, Nykjaer C, Woodhead C, et al. Dietary fibre intake and risk of cardiovascular disease: systematic review and meta-analysis. BMJ. 2013;347:f6879.

25. Roth GA, Johnson C, Abajobir A, Abd-Allah F, Abera SF, Abyu G, et al. Global, regional, and national burden of cardiovascular diseases for 10 causes, 1990 to 2015. J Am Coll Cardiol. 2017;70(1):1-25.

26. Guerriero G, Berni R, Munoz-Sanchez JA, Apone F, Abdel-Salam EM, Qahtan AA, et al. Production of plant secondary metabolites: examples, tips and suggestions for biotechnologists. Genes (Basel). 2018;9(6):309. https://doi. org/10.3390/genes 9060309

27. Jung BM, Shin TS, Heo YR. Comparison of volatile compounds identified in different parts of Peucedanum japonicum Thunberg by harvest time. J Korean Soc Food Sci Nutr. 2014;43(12):1871-80.

28. Lee EK, Shin MC, Jung SH. Volatile compound analysis and anti-oxidant and anti-inflammatory effects of Oenanthe javanica, Perilla frutescens, and Zanthoxylum piperitum essential oils. Asian J Beauty Cosmetol. 2017;15(3): 355-66.

29. Wang Y, Li X, Jiang $Q$, Sun H, Jiang J, Chen S, et al. GC-MS Analysis of the volatile constituents in the leaves of 14 compositae plants. Molecules. 2018; 23(1).

30. Ebrahimabadi AH, Movahedpour MM, Batooli H, Ebrahimabadi EH, Mazoochi A, Qamsari MM. Volatile compounds analysis and antioxidant, antimicrobial and cytotoxic activities of Mindium laevigatum. Iran J Basic Med Sci. 2016; 19(12):1337-44.

31. Zhou RR, Cai WX, Xu BJ. Phytochemical profiles of black and yellow soybeans as affected by roasting. Int J Food Prop. 2017;20(12):3179-90.

32. Serban MC, Sahebkar A, Zanchetti A, Mikhailidis DP, Howard G, Antal D, et al. Effects of quercetin on blood pressure: a systematic review and metaanalysis of randomized controlled trials. J Am Heart Assoc. 2016;5(7).

33. Bule M, Abdurahman A, Nikfar S, Abdollahi M, Amini M. Antidiabetic effect of quercetin: a systematic review and meta-analysis of animal studies. Food Chem Toxicol. 2019;125:494-502.

34. Mohammadi-Sartang M, Mazloom Z, Sherafatmanesh S, Ghorbani M, Firoozi D. Effects of supplementation with quercetin on plasma C-reactive protein concentrations: a systematic review and meta-analysis of randomized controlled trials. Eur J Clin Nutr. 2017:71(9):1033-9.

35. Koczurkiewicz P, Czyz J, Podolak I, Wojcik K, Galanty A, Janeczko Z, et al. Multidirectional effects of triterpene saponins on cancer cells - mini-review of in vitro studies. Acta Biochim Pol. 2015;62(3):383-93.

36. Holt SH, Miller JC, Petocz P, Farmakalidis E. A satiety index of common foods. Eur J Clin Nutr. 1995;49(9):675-90.

37. Lim HJ. Fullness factor diet: you can lose weight by eating as much as you want? Chosun Ilbo, Seoul; 2005.
38. Chambers L, McCrickerd K, Yeomans MR. Optimising foods for satiety. Trends Food Sci Tech. 2015:41(2):149-60.

39. Slavin JL. Dietary fiber and body weight. Nutrition. 2005;21(3):411-8.

40. Howarth NC, Saltzman E, Roberts SB. Dietary fiber and weight regulation. Nutr Rev. 2001;59(5):129-39.

41. Lee MS. The dietary habits of the nonagenarian population in longevity belt in Korea. Korean J Community Nutr. 2005;10(4):513-24.

42. Lee MS. Dietary habits and nutritional characteristics of Korean centenarians Food Industry Nutr. 2011;16(2):27-33.

43. Kontis V, Bennett JE, Mathers CD, Li G, Foreman K, Ezzati M. Future life expectancy in 35 industrialised countries: projections with a Bayesian model ensemble. Lancet. 2017;389(10076):1323-35.

44. World Health Statistics 2018. Monitoring health for the SDGs. Geneva: World Health Organization; 2018

45. Park SC. Ethnic food for longevity pursuit: assessment of Korean ethnic food. J Ethn Foods. 2016;3:167-70.

46. Kwon DY. Hansikinmunhak. 2019 (In press).

\section{Publisher's Note}

Springer Nature remains neutral with regard to jurisdictional claims in published maps and institutional affiliations.
Ready to submit your research? Choose BMC and benefit from:

- fast, convenient online submission

- thorough peer review by experienced researchers in your field

- rapid publication on acceptance

- support for research data, including large and complex data types

- gold Open Access which fosters wider collaboration and increased citations

- maximum visibility for your research: over $100 \mathrm{M}$ website views per year

At $\mathrm{BMC}$, research is always in progress.

Learn more biomedcentral.com/submissions 